\title{
Foraminifera iodine to calcium ratios: approach and cleaning
}

\author{
HELGE ARNE WINKELBAUER ${ }^{1}$, KATHY CORDOVA ${ }^{2}$, \\ DHARMA ANDREA REYES-MACAYA ${ }^{3}$, JENNIFER \\ SCOTT $^{1}$, NICOLAAS GLOCK ${ }^{4}$, SIMON CHENERY ${ }^{5}$, \\ ELLIOTT HAMILTON ${ }^{5}$, PHILIP HOLDSHIP ${ }^{6}$, CHARLOTTE \\ DORMON $^{6}$ AND BABETTE HOOGAKKER ${ }^{1}$ \\ ${ }^{1}$ Heriot-Watt University \\ ${ }^{2}$ Universidad Peruana Cayetano Heredia \\ ${ }^{3}$ MARUM-Center for Marine Environmental \\ Sciences/University of Bremen \\ ${ }^{4}$ GEOMAR Helmholtz Centre for Ocean Research Kiel \\ ${ }^{5}$ British Geological Survey \\ ${ }^{6}$ University of Oxford \\ Presenting Author: haw2@hw.ac.uk
}

Iodine to calcium ratios in planktic and benthic foraminifera have been proposed as new proxy to assess subsurface and bottom water oxygenation in the past. Analysing iodine is more challenging than trace metals due to the volatility of iodine in acid solution and the lower ionisation potential. Here we compare previous analyses that used tertiary amine for stabilising iodine after dissolution with the alternative bases tetramethylammonium hydroxide (TMAH) and ammonium hydroxide $\left(\mathrm{NH}_{4} \mathrm{OH}\right)$. We also test the effect of different cleaning steps and samples sizes on benthic and planktic foraminiferal $\mathrm{I} / \mathrm{Ca}$ ratios. Both TMAH and $\mathrm{NH}_{4} \mathrm{OH}$ show comparable results to the tertiary amine method with low $\mathrm{I} / \mathrm{Ca}$ values in foraminiferal calcite from subsurface and bottom waters with low oxygen concentrations and higher I/Ca for well oxygenated water. This suggests that both alternative methods are suitable for stabilizing iodine dissolved in acid. The number of foraminiferal tests analysed influences the spread of I/Ca. Samples containing 5 to 10 tests have a much wider spread compared with samples containing 20 or more tests. The clay removal steps during cleaning cause the largest reduction of iodine contamination similar to cleaning for $\mathrm{Mg} / \mathrm{Ca}$ analysis. Samples from poorly oxygenated sites with moderate to high organic carbon contents show the largest iodine contamination. We recommend doubling the oxidative cleaning step ( 4 instead of 2 steps) to ensure that all organic material is removed. 